\title{
A IMPORTÂNCIA DA METODOLOGIA CIENTÍFICA NA CONSTRUÇÃO DA CIÊNCIA
}

\section{ARTIGO ORIGINAL}

BLOISE, Denise Martins ${ }^{1}$

BLOISE, Denise Martins. A importância da metodologia científica na construção da ciência. Revista Científica Multidisciplinar Núcleo do Conhecimento. Ano 05, Ed. 06, Vol. 06, pp. 105-122. Junho de 2020. ISSN: 2448-0959, Link de acesso: https://www.nucleodoconhecimento.com.br/educacao/metodologia-cientifica

\section{RESUMO}

Método significa caminho, uma forma de proceder, de realizar tarefas, atividades, propostas. A metodologia é uma ciência que estuda o caminho, se propõe a fazer uma reflexão sobre o caminho. Em uma pesquisa, o que se busca é o conhecimento; procura-se conhecer um pouco mais sobre determinado assunto, certa questão que não se conhece tão bem, algum aspecto que precisa ser aprofundado. A metodologia é o instrumento de que a pesquisa se utiliza para construir o conhecimento, conhecimento esse que permita fazer a discussão proposta pela pesquisa. No estudo em questão, buscamos perceber a essência do pensamento científico e como ele opera em contraste com o senso comum. Destacamos a importância fundante do método na ciência. $O$ objetivo é compreender como realizar uma pesquisa científica. Este estudo baseou-se em uma ampla revisão bibliográfica e na experiência da pesquisadora enquanto tal e enquanto professora de metodologia da pesquisa científica há décadas.

${ }^{1}$ Doutora em Psicossociologia de Comunidades e Ecologia Social (UFRJ - 2013). Mestre em Educação: Educação Especial e Educação Ambiental (UERJ - 1993). Especialista em Educação Ambiental (Pós-Graduação) - (UCAM/ JBRJ - 2009). Graduação: Pedagogia (Supervisão Administração 1ํ Grau) CCHS - 1983. 
Palavras-chave: Pesquisa, metodologia, ciência.

\section{INTRODUÇÃO}

O trabalho de uma pesquisa é sair do senso comum e ir para o conhecimento científico e filosófico. Procura-se transformar boas ideias em um projeto de pesquisa com objetividade e rigor. A realização de uma pesquisa exige a consciência do ponto em que estamos e do ponto aonde almejamos chegar, ou seja, precisamos ter um objetivo de trabalho definido. O pesquisador precisa ter claro o que ele quer resolver, qual é a sua busca, qual a sua questão de pesquisa, qual o problema a ser resolvido. Esse primeiro passo define todo o processo de pesquisa. É o momento no qual o pesquisador estrutura a proposta da pesquisa, contextualizando-a no espaço acadêmico.

A metodologia vai organizar a pesquisa, estabelecendo os caminhos a serem seguidos a fim de que se alcancem os objetivos. Ao escolhermos a metodologia, definimos o tipo de pesquisa a ser desenvolvida e como esse trabalho seguirá até sua conclusão: os passos a serem dados, os instrumentos utilizados e a forma como os dados de estudo serão coletados.

A pesquisa científica, seja de que tipo for, segue a evolução do pensamento científico, que se pauta pelos paradigmas científicos que regem cada momento da história. Os paradigmas ordenam e guiam a sociedade e seus períodos históricos. Kuhn (1989) conceitua os paradigmas como as conquistas científicas que são aceitas e validadas por todos e, que oferecem respostas para uma coletividade específica.

Os paradigmas, portanto, funcionam como um modelo, um sistema de verdades cientificamente comprovadas, através do qual a sociedade se alinha e passa a funcionar com regularidade.

O conhecimento científico se opõe ao conhecimento proveniente do senso comum, pois é comprovado pela ciência através de métodos científicos, do uso da razão e da lógica. O senso comum é um conhecimento proveniente da sabedoria popular, da 
intuição e da tradição, sem comprovação da ciência. A ciência se utiliza de métodos cuidadosa e meticulosamente elaborados, que obedecem a etapas muito bem organizadas e a uma linguagem comum, métodos esses adequados a cada tipo e linha de pesquisa. Esse rigor científico é necessário para que toda a comunidade científica compreenda o que se está a transmitir.

O método de pesquisa utilizado neste estudo foi a revisão bibliográfica, realizando-se uma busca em sites como a SciELO, Google Acadêmico, Site da CAPES, Biblioteca Digital de diversas universidades e em livros da área específica de conhecimento. A vasta experiência da pesquisadora enquanto professora de metodologia da pesquisa científica e enquanto pesquisadora foi decisiva para a fundamentação do estudo.

No primeiro capítulo é feita uma breve apresentação da pesquisa. O segundo capítulo procura definir os conceitos de pesquisa e metodologia. O terceiro capítulo aborda o pensamento científico, relatando sua evolução histórica e os seus paradigmas, e trazendo para o debate a questão do senso comum versus o conhecimento científico. O quarto capítulo focaliza a pesquisa científica e suas particularidades. Reservou-se a última parte do estudo às considerações finais.

\section{DEFINIÇÕES E CONCEITOS}

\subsection{PESQUISA - O QUE É}

Uma pesquisa pode ser conceituada enquanto um mecanismo coerente, lógico, organizado e meticuloso cuja finalidade é fornecer respostas às questões levantadas. A necessidade de pesquisa deve-se à falta de dados e informações imprescindíveis para a solução do problema levantado. Mas a pesquisa também se mostra indispensável quando estes dados e/ou informações estão desorganizados e caóticos, revelando-se incapazes de fornecer o necessário suporte à questão.

Gil (2002) afirma que uma pesquisa acontece quando, baseando-se no conhecimento existente, são utilizadas metodologias, técnicas e ferramentas científicas na busca e construção do conhecimento. O processo da pesquisa científica compreende diversas 
etapas que começam com a elaboração de um problema até chegar à comunicação dos resultados.

Uma pesquisa torna possível compreender determinado fenômeno, seu aparecimento, desenvolvimento e processos de elaboração. Segundo Rudio (1986), de uma forma mais abrangente, a pesquisa constitui-se enquanto uma reunião de procedimentos orientados para a procura de um conhecimento específico. Para ser classificada como científica, é necessário que a pesquisa siga uma sistemática própria, uma ordem e metodologia específicas, normas determinadas, ou seja, que persiga os métodos e técnicas estabelecidos pela ciência.

A pesquisa se configura enquanto uma busca por respostas e/ou soluções para um problema, uma questão, uma inquietação, uma curiosidade. O professor e pesquisador Pedro Demo (1994) afirma que a pesquisa é a principal demanda a ser enfrentada pela academia e pela educação contemporânea.

$\mathrm{Na}$ condição de princípio científico, pesquisa apresenta-se como a instrumentação teórico-metodológica para construir conhecimento. Como princípio educativo, pesquisa perfaz um dos esteios essenciais da educação emancipatória, que é o questionamento sistemático crítico e criativo. Neste sentido, educar e construir conhecimento podem aproximar-se, e, em alguns momentos, mesmo coincidir, desde que não se mistifique a construção de conhecimento, que é apenas meio. A educação possui, ademais, a relação com fins, valores, afetos e sentimentos, cidadania e direitos humanos, aos quais os meios deverão servir (DEMO, 1994, p.33).

Demo (1994) estabelece que a função da pesquisa vai além da atividade própria da academia, devendo ser uma atitude diária do professor e do cidadão. A pesquisa, de acordo com o autor, é o que define o professor. Para Demo (1994), professor que não constrói conhecimento não pode ser classificado enquanto tal. 
Pesquisar não é simplesmente seguir regras e normas metodológicas. A pesquisa científica, como explica Goldenberg (2009), requer inovação, originalidade, método, ordenação e simplicidade, numa busca de harmonizar as possibilidades com as impossibilidades, e o conhecimento com o obscurantismo.

Minayo (2009) identifica a pesquisa como a atividade fundante da ciência em seu processo de busca e elaboração do conhecimento real. A pesquisa tem a função de fornecer a matéria-prima para o ato de ensinar, renovando-o e modernizando-o em função da realidade da vida e do mundo. A autora segue afirmando que a pesquisa, enquanto uma atividade teórica, estabelece uma ligação entre pensamento e ação. Isto significa dizer que uma questão precisa primeiro ser um problema da vida prática para depois se tornar um problema intelectual. As demandas ou indagações de pesquisa estão condicionadas a situações e inclinações coletivas, próprias da vida em sociedade.

Lakatos e Marconi (1987) reconhecem a pesquisa enquanto uma atividade formal, que demanda uma abordagem científica, com método e pensamento reflexivo, que busca o conhecimento da realidade enquanto um todo ou suas partes. "Significa muito mais do que apenas procurar a verdade: é encontrar respostas para questões propostas, utilizando métodos científicos" (LAKATOS e MARCONI, 1987, p.44).

\subsection{O QUE VEM A SER METODOLOGIA}

A metodologia é o que vai dar ordem, estruturação lógica à busca empreendida pelo pesquisador, fornecendo a direção a ser seguida. Segundo o dicionário de português on-line, metodologia é um conjunto de "regras ou normas estabelecidas para o desenvolvimento de uma pesquisa; uma parte da ciência que se dedica aos procedimentos organizados, aos métodos, utilizados pela própria ciência".[2]

Goldenberg (2009) infere que a metodologia ensina o pesquisador a ter um olhar crítico e científico, desenvolvendo nele o pensamento científico, criativo, organizado, claro e crítico. 
A metodologia é o que tornará possível, de acordo com Demo (1994), a definição dos passos metodológicos determinantes do caminho que o pesquisador vai seguir, identificar as partes, métodos, técnicas, leituras, discussões e a base teórica a serem trilhadas durante a busca. O questionamento deve ser sempre o método da pesquisa.

O método ou processo metodológico, segundo Severino (2007), refere-se ao instrumental tecnológico, à utilização de uma prática de pesquisa escolhidos e/ou definos pelo pesquisador. "A ciência se faz quando o pesquisador aborda os fenômenos aplicando recursos técnicos, seguindo um método e apoiando-se em fundamentos espistemológicos" (SEVERINO, 2007, p.100).

Mattar (2005) reconhece o método como sendo formado por duas partes:

Como método imaginamos, primeiro, um procedimento, isto é, uma sequência de diferentes comportamentos a serem adotados por um ou vários indivíduos e/ou automatizada até um nível em que seja possível esse procedimento ser 'transmitido' e 'utilizado' por pessoas que nunca teriam sido capazes de inventá-lo. Mas também imaginamos método como um segundo componente, objetivos específicos ou soluções específicas que tal procedimento nos ajudará a (ou poderá até mesmo nos prometer) alcançar (MATTAR, 2005, p.9).

Castro (1977) explica que a metodologia preserva a ciência das falhas e ambiguidades. Pois não existe no método científico a possibilidade de "gostar ou não, achar ou não", tudo na ciência deve ser comprovado pela pesquisa empírica ou teórica.

Lakatos e Marconi (1987) lembram que a determinação da metodologia é essencial, pois responde a diversas questões fundantes para a pesquisa: "como?, com quê?, onde?, quanto?' (LAKATOS e MARCONI, 1987, p.105). 


\section{O PENSAMENTO CIENTÍFICO}

\subsection{EVOLUÇÃO HISTÓRICA DO PENSAMENTO CIENTÍFICO}

O pensamento científico tem evoluído no decorrer da história da humanidade com base nos paradigmas da ciência, que vêm, da mesma forma, se transformando ao longo do tempo. A história comprova a permanente evolução dos paradigmas científicos. A espécie humana progride e se desenvolve com dinamismo e de forma continuada, e como consequência natural seus conceitos, suas ideias, suas crenças e seus valores também se transformam. "Segundo Assmann (1998), não há paradigma permanente, pois eles são historicamente mutáveis, relativos e naturalmente seletivos"(ASSMANN, 1998 apud OLIVEIRA, s/d. p.1). Acompanhar tal processo de mudanças na sociedade e na ciência requer uma mente aberta, curiosa, crítica e também estudo e espírito de pesquisa.

Paradigmas fornecem o arcabouço estrutural da sociedade, em particular do mundo científico, estabelecendo modelos que permitem a compreensão da realidade. É preciso, porém, acautelar-se para que esses mesmos paradigmas não restrinjam a visão de mundo, o que acontece quando as pessoas teimam em se ater a um paradigma conservador, que já não corresponde ao momento atual. Oliveira (s/d) compara a função dos paradigmas à função dos óculos, que tornam possível a leitura de um texto, clareiam a visão; da mesma forma os paradigmas permitem a leitura da realidade, tornando-a compreensível. Os paradigmas estabelecem a aceitação e definição do que é certo e do que é errado, tanto para a comunidade científica quanto para a população. A prática dos professores é, da mesma forma, norteada pelos paradigmas vigentes.

Kuhn (1989) reconhece o papel dos "paradigmas" na pesquisa científica e os relaciona ao que ele define como "ciência normal", ou seja, a que contém a "gênese e a continuação de uma tradição de pesquisa determinada" (KUHN, 1989, p.31). O autor conceitua paradigma enquanto os feitos e contribuições da ciência, aceitos de forma universal e que apresentam soluções para as questões durante um determinado período para um grupo de cientistas. 
Quando ocorre a mudança de um paradigma para outro, surgindo um novo paradigma, ocorre o que Kuhn (1989) denomina "revolução científica". Assim como as revoluções políticas nascem de uma crescente insatisfação com a situação das instituições vigentes, as revoluções científicas nascem de uma inquietação relativa à ciência.

De forma muito semelhante, as revoluções científicas iniciam-se com um sentimento crescente, também seguidamente restrito a uma pequena subdivisão da comunidade científica, de que o paradigma existente deixou de funcionar adequadamente na exploração de um aspecto da natureza, cuja exploração fora anteriormente dirigida pelo paradigma (KUHN, 1989, p.126).

Segundo Roque (s/d), uma questão importante, levantada pelo linguista norteamericano Steven Pinker (1989), refere-se ao nascimento da ciência, a qual não surgiu de forma repentina e tão pouco foi inventada como num passe de mágica. Ela seguiu um caminho evolutivo, paralelamente à descoberta de técnicas e instrumentos novos, possibilitando a adoção de hábitos e comportamentos diferentes, trazendo formas de pensamentos originais, procurando explicar os fenômenos circundantes. Roque (s/d) afirma que a evolução do homem, que vem acontecendo há milhões de anos, provocou o desenvolvimento de habilidades artísticas, religiosas e científicas na mente do ser humano.

A evolução da ciência continua até os dias de hoje, e vai continuar, pois é permanente e ininterrupta. O homem segue seu processo evolutivo através do tempo, segue caminhando, agindo e transformando a natureza e a realidade, como um ser pensante e reflexivo.

\subsection{OS PARADIGMAS DA CIÊNCIA}

Toda pesquisa é amparada por um paradigma. Os paradigmas da ciência, ou paradigmas epistemológicos, sustentam e dão a direção da metodologia da pesquisa científica. Assim como a sociedade vem passando por mudanças ao longo do tempo, 
a forma e maneira como a ciência é construída também sofre transformações, uma vez que a ciência é estruturada através das condições materiais do homem.

O primeiro paradigma da ciência baseou-se numa explicação sobrenatural da vida e dos fenômenos da natureza. Os deuses explicavam a vida na terra e o acesso ao conhecimento se dava através dos mitos. A organização natural, social e psíquica da vida era explicada pela existência de dois mundos - o mundo real e o mundo sobrenatural (ARAÚJO in CAMARGO e SANTOS, 2010; BEHRENS e OLIARI, 2007).

O segundo paradigma da ciência trouxe uma visão racional da vida e da natureza, que continha em si a explicação da ordem dos fenômenos. Correspondeu ao período entre os séculos VII e VI a.C., na Grécia Antiga, e ficou conhecido como a Era da Teoria do Conhecimento Clássico. Araújo (in CAMARGO e SANTOS, 2010) afirma que esse período preconizava a razão para explicar o mundo e, sendo assim, a ciência fazia uso dessa abordagem racional, discursiva e que necessitava de comprovação. Essa visão, de acordo com o autor, elimina as sensações e as percepções, estabelecendo que a verdade somente pode ser alcançada através do uso da razão.

O terceiro paradigma da ciência surgiu na Idade Média, do século I ao século XIII, quando aflora a Teoria do Conhecimento. A visão Teocêntrica define o homem como uma criatura proveniente de Deus e as verdades são conhecidas através da fé e das Escrituras Sagradas. A verdade da fé substitui a verdade da razão, Deus é o valor supremo, está no centro de tudo. A ciência avançou muito pouco nesse período, pois os cientistas sofriam perseguição por parte da Igreja.

Nesse sentido, cabe a contribuição de Lara (1991, p. 25), que acrescenta: "Reconheciam os medievais que a razão humana pode descobrir muita coisa, pois pode pesquisar, raciocinar, inventar. Mas existem verdades supremas que a razão não chega a conhecer, pensavam eles.Essas Deus revelou. Estão na Bíblia" (BEHRENS e OLIARI, 2007, p.56). 
O paradigma seguinte traz a visão Antropocêntrica. É o período do Renascimento, do século III ao século $X V$, quando são rejeitadas as crenças no mito e na fé. Nesse período as ideias de Copérnico e Galileu provocam uma verdadeira revolução científica, se opondo e se confrontando à Igreja e a seus dogmas seculares. A Terra e o homem não eram o centro do Universo, era a Terra que girava em torno do Sol.

Acaba, portanto, com a visão de que o homem é o centro absoluto do Universo e dá origem a uma abordagem empírica de ciência. Abordagem esta calcada nos princípios positivistas, em que só é verdade o que pode ser observado, mensurado, quantificado, controlado e reproduzido. Visão caracterizada pela descrição matemática dos fenômenos. A subjetividade era considerada como projeção mental (ARAÚJO in CAMARGO e SANTOS, 2010, p. 94).

É a visão linear e mecanicista do Universo elaborado por Newton e Descartes, fundamentada na lógica racionalista, que rejeita a lógica do sagrado e a subjetividade. "Nesse modelo de ciência, segundo Capra (1996), o homem é o senhor do mundo, pois se dá o direito de transformar, explorar, servir-se e escravizar a natureza" (ARAÚJO in CAMARGO e SANTOS, 2010, p. 94).

Com o advento da Idade Moderna, século XV ao século XVIII, o conhecimento é tido como uma certeza total, absoluta e inquestionável. O pensamento científico sofre uma revolução, com a razão centrada na matemática, a natureza torna-se um objeto passível de mensuração e observação. O pesquisador, dentro dessa visão, necessita desmembrar um sistema em partes para conhecer o seu correto funcionamento. Behrens e Oliari (2007) inferem ser esse o paradigma cartesiano, que acredita na veracidade de fatos inquestionáveis e de amplo conhecimento. Esse método parte da análise através da indução e dedução, fundado na lógica e na matemática.

Ao final do século XVII e início do século XIX, o segundo período da modernidade, tem início a busca pelo entendimento do homem, da pessoa humana, de sua personalidade e inteligência. A Psicologia se separa da Filosofia e as teorias psicológicas afloram e ganham destaque no mundo da ciência, assim como a 
Sociologia. Porém, somente eram aceitas afirmações que passassem pelo crivo da lógica positivista. As pesquisas apresentavam dados de experiências e observações consideradas confiáveis pela racionalidade científica, aceitando apenas afirmações impessoais desprovidas de posições pessoais ou juízos de valor. O paradigma newtoniano-cartesiano ou paradigma tradicional provocou uma fragmentação do conhecimento e uma supervalorização da visão racional.

Esse paradigma, de acordo com Behrens e Oliari (2007), condenou a humanidade à fragmentação, atomização e desligamento, separando-a da natureza, do trabalho e de sua própria essência. Como consequência acontece um rompimento dos valores culturais, individualizando-os e tornando a vida mais patológica.

Ao final do século XIX e início do século XX, surge a Terceira Fase da Modernidade, trazendo confrontos e embates com os padrões vigentes da ciência. Um novo padrão emerge, que ficou conhecido como Paradigma da Complexidade e cujo foco é a visão do ser humano integral e holístico. O que se busca é uma revisão do processo fragmentado e reducionista, objetivando reunir conhecimentos e visões, em prol de um olhar integral do homem, da natureza, da ciência, reunida as contribuições das diversas ciências.

O paradigma da complexidade propõe uma visão de homem indiviso, que participa da construção do conhecimento não só pelo uso da razão, mas também aliando as emoções, os sentimentos e as intuições. Nesse sentido, torna-se urgente que as estruturas do funcionamento educacional incluam o uso dos conceitos de inter, pluri e transdisciplinar (BEHRENS e OLIARI, 2007, p.63).

Neste contexto, pode-se considerar que o novo paradigma começa a encontrar espaços para dar respostas mais relevantes para os problemas da humanidade. Na natureza, tudo é cíclico; assim, cabe refletir que o movimento natural de entropia no universo pode gerar a crise e o caos, mas permite rever, rediscutir e construir novas possibilidades. A nova reorganização precisa restituir ao homem e, por 
extensão, a natureza, o que foi perdido com a proposição do pensar tradicional, do capitalismo exacerbado e mais recentemente, da globalização desenfreada e descomedida (BEHRENS e OLIARI, 2007, p.65).

\subsection{SENSO COMUM X CONHECIMENTO CIENTÍFICO (ou $O$ CONHECIMENTO CIENTÍFICO E O SENSO COMUM)}

O senso comum refere-se aos modos de pensar e pontos de vista que surgem do cotidiano. São os conceitos e ideias aceitos como verdade por um grupo social sem questionamento ou comprovação científica. Quando a ciência testa e experimenta esses conceitos, corroborando suas verdades, eles são, então, apropriados pela ciência, passando à categoria de conhecimento científico. O senso comum se distancia do conhecimento científico em função do aperfeiçoamento metodológico que a ciência elabora. "A pesquisa científica tem início no conhecimento vulgar; porém, dele se diferencia através de metodologias e princípios que visam a legitimá-la enquanto conhecimento científico" (FRANCELIN, 2004, p.31).

O senso comum se caracteriza pela ausência de uma fundamentação ordenada e lógica, muito mais do que pela veracidade ou falsidade de suas premissas. As informações e ideias são transmitidas e repassadas sem que se saiba o motivo, a causa ou o significado delas.

São processos acríticos nos quais um indivíduo concebe um conjunto de informações como conhecimentos, sem saber realmente o que significam, e os utiliza na prática cotidiana como se fossem verdadeiros e definitivos, sendo estes últimos apenas "conhecimentos provisórios e parciais" (Cotrim, 2002, p.47) (FRANCELIN, 2004, p.31).

Os conhecimentos científicos podem, igualmente, ser provisórios e parciais, pois no decorrer do tempo surgem pesquisas novas que produzem conhecimentos novos. Francelin (2004) ressalta como um grande diferencial o fato de existir, no meio científico, total compreensão de que nenhuma pesquisa é definitiva. A ciência evolui 
e sempre surgem novos conhecimentos comprovados. Já o senso comum acredita em verdades definitivas. Todo o rigor da ciência procura distanciar-se do senso comum.

O conhecimento proveniente do senso comum, ou conhecimento vulgar, como também é chamado, possui pontos em comum e pontos conflitantes com o conhecimento científico. Com o passar do tempo, a comunidade científica vem mudando sua postura em várias áreas e uma delas refere-se à divulgação do conhecimento científico, que vem sendo oferecido tanto ao público especializado (pares) quanto ao público leigo (senso comum). A ciência vem se mostrando mais flexível em relação às suas teorias e métodos.

Um campo de conhecimento talvez não baste por si só e parece que não constrói conhecimento sem a relação com o oposto. Isso significa que, como já exposto, a ciência necessita do senso comum, que a razão necessita do mito, que a crença pode manifestar-se a partir dos mais rigorosos métodos científicos, que as revoluções dependem de uma suposta verdade, e essa verdade vem do ser humano. Assim, as configurações de verdade, mesmo as científicas e, talvez, principalmente essas, carregam em si as maiores provas e os mais nítidos exemplos de medo, angústia, amor, fé, júbilo filosófico e contemplação na mais alta rigorosidade metodológica e ceticismo científico, pois o espírito científico é metafórico (FRANCELIN, 2004, p.33).

Gil (2008) afirma que o conhecimento científico é a forma mais segura de conhecimento, e todos os demais (conhecimento vulgar, religioso e filosófico) são capazes de equívocos e falhas. O conhecimento científico objetiva elaborar, através de linguagem própria, sistemática e que impõe rigor, leis que governam os fenômenos.

Pode-se definir ciência mediante a identificação de suas características essenciais. Assim, a ciência pode ser caracterizada como uma forma de conhecimento objetivo, racional, sistemático, geral, verificável e falível. 
O conhecimento científico é objetivo porque descreve a realidade independentemente dos caprichos do pesquisador. E racional porque se vale, sobretudo, da razão, e não de sensação ou impressões, para chegar a seus resultados. É sistemático porque se preocupa em construir sistemas de ideias organizadas racionalmente e em incluir os conhecimentos parciais em totalidades cada vez mais amplas. E geral porque seu interesse se dirige fundamentalmente à elaboração de leis ou normas gerais, que explicam todos os fenômenos de certo tipo. $E$ verificável porque sempre possibilita demonstrar a veracidade das informações. Finalmente, é falível porque, ao contrário de outros sistemas de conhecimento elaborados pelo homem, reconhece sua própria capacidade de errar (GIL, 2008, p. 2 e 3).

\section{A PESQUISA CIENTÍFICA}

\subsection{O MÉTODO NA CIÊNCIA}

O método é o que define a ciência enquanto tal. O objetivo da ciência é buscar a autenticidade dos fatos, e o que distingue o conhecimento científico dos demais é sua capacidade de ser mensurável e de ser verificado.

Método significa caminho. Escolher um método é definir um caminho para se atingir um objetivo. O método científico é o caminho através do qual a ciência busca experimentar, medir, provar, verificar suas hipóteses e teorias. Segundo Gil (2008), o método científico é definido "como o conjunto de procedimentos intelectuais e técnicos adotados para se atingir o conhecimento" (GIL, 2008, p.8).

Severino (2007) conceitua o método científico como o método próprio da ciência, que é essencial para a construção do conhecimento. O autor diferencia o conhecimento científico, não apenas do senso comum, como também do que ele denomina como "expressões da subjetividade humana", a saber, a filosofia, a arte e a religião. 
Não há um método único que possa ser indistintamente aplicado a todas as áreas do conhecimento, a despeito do desejo de diversos pensadores do passado. A comunidade científica hoje reconhece uma pluralidade de métodos aplicáveis a diferentes pesquisas de acordo com o objetivo de cada uma, o objeto a ser investigado e os tipos de hipóteses, proposições e problemas pesquisados.

Assim, pode-se afirmar que a Matemática não tem o mesmo método da Física, e que esta não tem o mesmo método da Astronomia. E com relação às ciências sociais, pode-se mesmo dizer que dispõem de grande variedade de métodos (GIL, 2008, p.8).

Todo trabalho científico faz uso de um arsenal de técnicas e procedimentos em função da aplicação de um método de pesquisa escolhido. O método determina o rumo do trabalho de pesquisa, tudo o que for utilizado ou desenvolvido será em decorrência dessa escolha inicial, seguirá essa orientação determinada pela metodologia.

No entanto, não basta seguir um método e aplicar técnicas para se completar o entendimento do procedimento geral da ciência. Esse procedimento precisa ainda referir-se a um fundamento epistemológico que sustenta e justifica a própria metodologia praticada (SEVERINO, 2007, p.100).

\subsection{COMO REALIZAR UMA PESQUISA CIENTÍFICA}

Para realizar uma pesquisa científica é preciso aplicar o método científico. Antes de mais nada o pesquisador necessita ordenar as próprias ideias. Dessa forma ele transforma boas ideias em um trabalho de pesquisa com objetividade e rigor, sistematizando as questões a serem estudadas. Ele escolhe um tema de pesquisa que seja do seu interesse -- mais propriamente: que seja apaixonante. Em seguida o pesquisador deve recortar o seu tema, delimitando o objeto dentro de um campo de estudo e determinado as variáveis que serão observadas. É importante que a tarefa de pesquisa seja reduzida ao que é possível ser realizado. 
No momento seguinte o pesquisador define os conceitos que serão utilizados, estabelecendo o arcabouço teórico que vai sustentar o trabalho. Aqui ele define o método de pesquisa, como ele vai abordar o tema escolhido, qual a metodologia de pesquisa vai ser utilizada, que tipo de pesquisa ele vai desenvolver, que técnicas ele pretende utilizar.

O pesquisador precisa ter claro o porquê de ele ter escolhido esse tema, qual a justificativa de sua pesquisa; e para quê ele vai desenvolver o trabalho, qual o seu objetivo com essa pesquisa. Ele precisa também estabelecer um cronograma de trabalho, especificando as tarefas a serem desenvolvidas e em que momentos irá desenvolvê-las, prevendo dessa forma etapas que possivelmente serão reformuladas.

O passo seguinte é fazer um levantamento bibliográfico sobre o assunto, descobrindo os estudos anteriores sobre o tema e as contribuições que seu trabalho trará. Agora, então, ele passará a operacionalizar sua pesquisa, observando e coletando os dados, analisando, verificando os resultados, estabelecendo suas conclusões e redigindo sua pesquisa. É preciso um planejamento cuidadoso e bem estruturado.

A atitude do pesquisador deve ser a mais objetiva possível, procurando uma imparcialidade e certa distância do objeto de pesquisa, a fim de evitar o comprometimento da pesquisa com o favorecimento de determinadas posições na coleta e interpretação dos dados. Ele deve aprender a desenvolver o que Goldenberg (2009) chama de "olhar científico", exercitando o aprendizado do pensar cientificamente, com criatividade, organização, método, clareza e alegria. Ele deve ter uma mente curiosa e uma postura crítica.

\subsection{TIPOS DE PESQUISA CIENTÍFICA}

Partindo do pressuposto de que a pesquisa é a atitude básica da ciência na sua indagação e construção da realidade, existem três tipos de pesquisa quanto à forma de abordagem. A Pesquisa Qualitativa trabalha funções particulares, informações não quantificáveis, é descritiva e trabalha com interpretação de fenômenos e atribuição de significados. A Pesquisa Quantitativa trabalha com dados estatísticos, transforma em 
números os dados e informações coletados para serem categorizadas e analisadas. E um terceiro tipo, que vem ganhando cada vez mais força, a Pesquisa Combinada, que trabalha com dados estatísticos e análise qualitativa simultaneamente.

Em relação às modalidades, as pesquisas se classificam em grupos ou tipos:

*PESQUISA BIBLIOGRÁFICA: é a primeira etapa de toda pesquisa. Uma pesquisa pode ser só bibliográfica, aprofundando e ampliando o levantamento bibliográfico. Tem como objetivo recolher, selecionar, analisar e interpretar as contribuições teóricas já existentes sobre determinado assunto.

*PESQUISA DESCRITIVA: o pesquisador observa, registra, analisa e correlaciona fatos ou fenômenos (variáveis). Buscam-se frequências das variáveis, suas naturezas, características, causas, relações e associações entre variáveis.

*PESQUISA EXPLORATÓRIA: indicada quando se tem pouco conhecimento do assunto. Busca de maiores informações sobre determinado assunto de estudo. Planejamento flexível para possibilitar a consideração dos mais diversos aspectos de um problema.

*PESQUISA DE CAMPO: o pesquisador vai a campo; há uma participação radical dos sujeitos envolvidos nos processos de produção de conhecimento. Ela se divide em: PESQUISA-AÇÃO: o pesquisador tem papel ativo no processo da pesquisa; há a previsão de ação planejada de intervenção direta na realidade vivenciada; PESQUISA PARTICIPANTE: observação participante; há o envolvimento, mas não há previsão de ação planejada de intervenção direta na realidade vivenciada; e PESQUISA-AÇÃO PARTICIPANTE: participação e previsão de ação planejada; os envolvidos devem trabalhar como agentes sociais em igualdade de poder de decisão, respeitando-se as atribuições distintas; há compromisso político com a emancipação e ação reflexiva.

Há também estudos mais específicos, quais sejam: ESTUDO DE CASO, HISTÓRIA ORAL e HISTÓRIA DE VIDA. As técnicas utilizadas são a Observação, a Entrevista Estruturada, Semi-estruturada e Livre. 


\section{CONSIDERAÇÕES FINAIS}

O trabalho da pesquisa é um trabalho instigante e diríamos apaixonante. Pesquisar é adotar uma atitude diante da vida. O pesquisador tem a mente aguçada, curiosa e uma postura crítica frente ao mundo. Pesquisar é descobrir novos universos, é desvelar segredos ocultos.

Porém, temos que ter em mente que ao desenvolver uma pesquisa científica estamos sujeitos aos parâmetros e normas da ciência. Seja qual for o tipo de pesquisa a desenvolver, quantitativa, qualitativa, combinada, pesquisa bibliográfica, pesquisa de campo, pesquisa teórica, pesquisa empírica, ou outra qualquer, devemos obedecer às normas da Academia. Para que a pesquisa seja considerada científica, deve ela seguir as normas da ciência, da metodologia científica.

É importante a preocupação com o nosso leitor; seja ele leigo ou cientista, nosso trabalho deve estar compreensível, bastando para isso o cumprimento das normas científicas e uma escrita que revela coerência lógica e gramatical.

Uma parte fundamental do trabalho do pesquisador é formular muito bem e de forma correta a sua questão, elaborar a sua hipótese, formular muito bem o seu "problema". A observação criteriosa e cuidadosa, seja ela num trabalho de campo ou num trabalho apenas teórico, é de extrema importância. O pesquisador deve ter olhos atentos e a mente aberta; um espírito humilde e ao mesmo tempo ousado.

Pesquisar é abrir um mundo de possibilidades de forma cautelosa, crítica e científica. A pesquisa é o instrumento que faz a ciência avançar, possibilitando o progresso e desenvolvimento da humanidade.

\section{REFERÊNCIAS}

ARAÚJO, Renata Rodrigues de. Os Paradigmas da Ciência e Suas Influências na Constituição do Sujeito: A Intersubjetividade na Construção Conhecimento. In: CAMARGO, MRRM., org., SANTOS, VCC., collab. Leitura e escrita como espaços autobiográficos de formação [online]. São Paulo: Editora UNESP; São Paulo: 
Cultura Acadêmica, 2010. 140 p. ISBN 978-85-7983-126-3. Available from SciELO Books http://books.scielo.org .Acesso em: 23.01.2019.

BEHRENS, Marilda Aparecida e OLIARI, Anadir Luiza Thomé. A Evolução dos Paradigmas na Educação: do Pensamento Científico Tradicional à Complexidade. Diálogo Educ., Curitiba, v. 7, n. 22, p. 53-66, set./dez. 2007. Acesso em:18.01.2019. Disponível em: https://periodicos.pucpr.br/index.php/dialogoeducacional/article/view/4156

BLOISE, Denise Martins. Metodologia da Pesquisa Científica: Aula 1. 2018. 22 slides.

. Metodologia da Pesquisa Científica: Aula 2. 2018. 24 slides.

. Tipos de Pesquisa. 2018. 6 slides.

ANÁLISE DO PROCESSO DE ORGANIZAÇÃO DOS AGRICULTORES DA FAZENDA PEDRAS ALTAS, BREJAL, PETRÓPOLIS, RJ. Um Estudo de Caso à Luz da Produção Agroecológica. Tese (Doutorado em Psicossociologia de Comunidades e Ecologia Social), Rio de Janeiro: UFRJ, 2013.

CASTRO, Claudio de Moura. A Prática da Pesquisa. São Paulo: McGraw-Hill do Brasil, 1977.

DEMO, Pedro. Metodologia do Conhecimento Científico. São Paulo: Atlas, 2009.

Pesquisa e Construção do Conhecimento. Rio de Janeiro: Tempo Brasileiro, 1994.

FRANCELIN, Marivalde Moacir. Ciência, senso comum e revoluções científicas: ressonâncias e paradoxos. Ci. Inf., Brasília, v.33, n. 3, p.26-34, set./dez. 2004

GIL, Antônio Carlos. Métodos e Técnicas de Pesquisa Social. 6 ed. São Paulo: Atlas, 2008. 
. Como Elaborar Projetos de Pesquisa. 4 ed. São Paulo: Atlas, 2002.

GOLDENBERG, Mirian. A Arte de Pesquisar. 11를. Ed. Rio de Janeiro: Record, 2009.

KUHN, Thomas S. A Estrutura das Revoluções Científicas. 3 ed. São Paulo: Perspectiva, 1989.

LAKATOS, Eva Maria e MARCONI, Marina de Andrade. Metodologia do Trabalho científico. 2 ed. São Paulo: Atlas, 1987.

MATTAR, João. Metodologia Científica na Era da Informática. 2 ed. São Paulo: Saraiva, 2005.

MINAYO, Maria Cecília de Souza (organizadora). Pesquisa Social: Teoria, método e criatividade. 28 Ed. Petrópolis, RJ: Vozes, 2009.

OLIVEIRA, Marques Roberto Alves. Da Evolução Do Pensamento Científico A Complexidade Paradigmática Educacional Na Formação Dos Grupos Sociais. UEMA, Brasil. s/d.

ROQUE, Antônio C. A Origem do Pensamento Científico. Evolução dos Conceitos da Física - FFCLRP - USP - s/d. Acesso em: 11.01.2019. Disponível em: http://sisne.org/Disciplinas/Grad/EvolConcFis/origem_pensamento_cientifico.pdf

RUDIO, Franz Victor. Introdução ao Projeto de Pesquisa Científica. $13^{\mathrm{a}}$ ed. Petrópolis, RJ: Vozes, 1986.

SEVERINO, Antônio Joaquim. Metodologia do Trabalho Científico. 23 ed. São Paulo: Cortez, 2007.

\section{APÊNDICE - REFERÊNCIA DE NOTA DE RODAPÉ}

2. https://www.dicio.com.br/metodologia

Enviado: Fevereiro, 2020. 
Aprovado: Junho, 2020. 